\title{
TWO-STAGE PRIORITIZATION PROCEDURE FOR MULTIPLICATIVE AHP-GROUP DECISION MAKING
}

\author{
Changsheng $\mathrm{LIN}^{1}$, Gang KOU ${ }^{2}, \mathrm{Yi} \mathrm{PENG}^{3}$, Fawaz E. ALSAADI ${ }^{4}$ \\ ${ }^{1}$ School of Mathematics and Statistics, Yangtze Normal University, 408100 Chongqing, China \\ ${ }^{2}$ School of Business Administration, Southwestern University of Finance and Economics, \\ 611130 Chengdu, China \\ ${ }^{3}$ School of Management and Economics, University of Electronic Science and Technology of China, \\ No. 2006, Xiyuan Ave, West Hi-Tech Zone, 611731 Chengdu, China \\ ${ }^{4}$ Department of information Technology, Faculty of Computing and IT, \\ King Abdulaziz University, Jeddah, Saudi Arabia
}

Received 08 October 2019; accepted 23 December 2019

\begin{abstract}
In this paper, we propose two-stage prioritization procedure (TSPP) for multiplicative Analytic Hierarchy Process-group decision making (AHP-GDM), which involves determining the group priority vector based on the individual pair-wise comparison matrices (PCMs), simultaneously considering the consensus and consistency of the individual PCMs. The first stage of the TSPP involves checking and revising the individual PCMs for reaching the acceptable consensus and consistency. The second stage of the TSPP involves estimating the group priority vector using Bayesian approach. The main characteristics of the proposed TSPP are as follows: 1) It makes full use of the prior information as well as the sample information during the Bayesian revision of the individual PCMs and the Bayesian estimation of the group priority vector; 2) It ensures that the revised individual PCMs reach the acceptable consensus and consistency; 3) It enriches the aggregation methods for the collective preference in multiplicative AHP-GDM. Finally, two numerical examples are used to evaluate the applicability and effectiveness of the proposed TSPP by the comparisons with several other methods.
\end{abstract}

Keywords: group decision making, pair-wise comparison matrix, consensus, consistency, group priority vector.

JEL Classification: C11, C25.

\section{Introduction}

Group decision making (GDM) has been extensively studied and used in various areas such as society, economy, management, etc (Altuzarra et al., 2010; Dong et al., 2010; Wu \& Xu, 2012; Wu \& Kou, 2016; Jin et al., 2016, 2019; Li et al., 2018; Zhang, et al., 2019; Schotten \&

*Corresponding author. E-mail: kougang@swufe.edu.cn

This is an Open Access article distributed under the terms of the Creative Commons Attribution License (http://creativecommons. org/licenses/by/4.0/), which permits unrestricted use, distribution, and reproduction in any medium, provided the original author and source are credited. 
Morais, 2019). Generally, GDM aims to determine the collective preference by aggregating the individual preferences, and then select the available alternative among alternatives. In GDM, decision makers often need to provide their preferences over a set of alternatives or criteria by pair-wise comparison matrices (PCMs). The PCMs provided by decision makers are expressed by different preference structures such as multiplicative preference relation, intuitionistic fuzzy preference relation and hesitant fuzzy linguistic preference relation (Li et al., 2017; Liu et al., 2019; Wu et al., 2019).

Analytic Hierarchy Process (AHP) (Saaty, 1977) is converted to the multiplicative structure that is referred to as multiplicative AHP (Barzilai et al., 1987; Honert, 1998). Multiplicative AHP-GDM is one of the most important multi-criteria decision making (MCDM) (Kou et al., 2012, 2014, 2016, 2019) methods solving GDM-related problems. In multiplicative AHP-GDM, there are two traditional aggregation methods to determine the group priority vector: aggregation of the individual judgments (AIJ) and aggregation of the individual priorities (AIP) (Ramanathan \& Ganesh, 1994; Forman \& Peniwati, 1998). However, AIJ and AIP are sometimes less reliable during multiplicative AHP-GDM when some individual PCMs have not the acceptable consensus or consistency. Thus, it is necessary that the individual PCMs have the acceptable consensus and consistency in multiplicative AHP-GDM. In fact, consensus means the unanimous and complete agreements regarding the collective preference while consistency avoids the self-contradictions in the preference relationships. Recently, some developments have been reported recently regarding the consensus and consistency of the individual PCMs in multiplicative AHP-GDM (Altuzarra et al., 2010; B. Srdjevic \& Z. Srdjevic, 2013; Lin \& Kou, 2015; Li et al., 2017). However, lots of previous studies have tended to focus on either the consistency or the consensus for the individual PCMs. For example, Altuzarra et al. (2007) assumed that the group consensus exists among decision makers and then investigated the consistency of the individual PCMs and the group priority vector. Some researchers have investigated ways of measuring the consensus as well as the consensus-reaching process (Dong et al., 2010; Altuzarra et al., 2010; Wu \& Xu, 2012; Dong \& Saaty, 2014). Nevertheless, few researchers simultaneously considered the consensus and the consistency for the individual PCMs. In this study, we attempt to take into account the consensus as well as the consistency for the individual PCMs.

In multiplicative AHP, the judgments in the individual PCMs structured on one to nine scales are not almost precise owing to the complexity and the uncertainty involved in realworld decision making (Jong, 1984; Hahn, 2003; Dong et al., 2016). Thus, the judgments in the PCM may be assumed to be random variables with continuous distributions (Honert, 1998; Basak, 1998, 2001; Altuzarra et al., 2007; Barfod et al., 2016), such as Uniform distribution (Hauser \& Tadikamalla, 1996), Gamma distribution (Vargas, 1982), Lognormal distribution (Basak, 1990; Escobar \& Moreno-Jimenez, 2000), Normal distribution (Abdullah et al., 2017), Cauchy distribution (Lipovetsky \& Tishler, 1999) and Beta distribution (Jalao et al., 2014), etc. Decision makers have prior opinions concerning the judgments in the individual PCMs. From a Bayesian statistics viewpoint, the final opinions of decision makers may be synthesized from the posterior distribution updating their prior opinions. In multiplicative AHP, Bayesian approach provides a natural framework for both parameter inference and model selection (Bernardo \& Smith, 1994). For example, Basak (1998) calculated the poste- 
rior distributions of the judgments in the individual PCMs; Gargallo et al. (2007) proposed a Bayesian procedure for the group priorities; Altuzarra et al. (2007) developed a Bayesian prioritization procedure (BPP) for the group priorities; Hughes (2009) revised the consistent probabilities using Bayesian method in AHP; Altuzarra et al. (2010) determined the consensus of the individual PCMs using Bayesian approach in multiplicative AHP-GDM; Lin \& Kou (2015) revised the individual PCMs by Bayesian approach in multiplicative AHP-GDM.

As mentioned above, the individual PCMs should reach the acceptable consensus and consistency before determining the group priority vector. The judgments in the individual PCMs can be treated effectively using Bayesian approach. We propose two-stage prioritization procedure (TSPP) for determining the group priority vector, simultaneously considering the consensus and the consistency of the individual PCMs in multiplicative AHP-GDM. The first stage of the TSPP is to check the consensus and the consistency for the individual PCMs and subsequently revise the individual PCMs without the acceptable consensus and consistency. The second stage of the TSPP is to estimate the group priority vector using Bayesian approach.

The rest of this paper is structured as follows. Section 1 provides a review of the preliminary information, including prioritization methods, measure indices and criteria, definitions, and theorems used. Section 2 describes the TSPP for determining the group priority vector. In Section 3, the applicability and effectiveness of the TSPP are evaluated using two numerical examples, and its performance is compared with those of several other methods. Last Section lists the conclusions of the study along with the future research trends.

\section{Preliminary}

\subsection{Prioritization methods}

In multiplicative AHP, there exist two popular prioritization methods to derive the priority vector from a PCM: Eigenvector method (EM) and Logarithmic least squares method (LLSM), which are described below:

Suppose that $A=\left(a_{i j}\right)_{n \times n}$ is a PCM, and that $v=\left(v_{1}, v_{2}, \cdots, v_{n}\right)^{\prime}$ is the priority vector derived from the PCM by certain prioritization method.

\section{Eigenvector method (EM) (Saaty, 1980)}

The desired priority vector $v=\left(v_{1}, v_{2}, \cdots, v_{n}\right)^{\prime}$ is obtained by solving the linear system: $A v=\lambda v$, where $\lambda$ is the principal eigenvalue of $A$.

\section{Logarithmic least squares method (LLSM) (Crawford \& Williams, 1985)}

The desired priority vector $v=\left(v_{1}, v_{2}, \cdots, v_{n}\right)^{\prime}$ is formulated as a multiplicative, normalizing, and constrained optimization problem:

$$
\operatorname{Min} \sum_{i=1}^{n} \sum_{j=1}^{n}\left(\ln a_{i j}-\ln v_{i}+\ln v_{j}\right)^{2} .
$$

Note that the effects of EM and LSSM with respect to multiplicative AHP are very similar (Dong et al., 2008). 


\subsection{Measure indices and criteria}

In order to check whether a PCM has the acceptable consensus and consistency, several measure indices and criteria (Consistency ratio (CR), Opening coefficient (OC), Geometric cardinal consensus index (GCCI) and Geometric ordinal consensus index (GOCI)) are introduced below:

Consistency ratio (CR) (Saaty, 1980)

CR measures the consistency level of a PCM, which is denoted by

$$
C R=(\lambda-n) / R I(n-1),
$$

where $\lambda$ and $n$ are the principal eigenvalue and the order of the PCM, respectively, and $R I$ is the random consistency index (see Saaty, 1980). The threshold of CR is 0.1 (Saaty, 1980). If $\mathrm{CR}=0$, the PCM has the perfect consistency; If $0<\mathrm{CR}<0.1$, the PCM has the acceptable consistency; Otherwise, the PCM should be revised until $\mathrm{CR}<0.1$.

Opening coefficient (OC) (Altuzarra et al., 2007)

The OC is used to find the judgments that disagree with the preference structure preferred by the other decision makers, which is denoted by

$$
\left.O C_{i j}=\underset{k \in\{1,2, \cdots, r\}}{\operatorname{Max}\left\{a_{i j}^{(k)}\right\}} / \operatorname{Min}_{k \in\left\{a_{i j}^{(k)}\right\}}\right\}(i, j=1,2, \cdots, n),
$$

where $A^{(k)}=\left(a_{i j}^{(k)}\right)_{n \times n}$ is the $k t h$ individual PCM. We employ OC as a consensus tool to find the judgments breaking the consensus in the individual PCMs. These found judgments should be revised for reaching the acceptable consensus.

Geometric cardinal consensus index (GCCI) (Dong et al., 2010)

The consensus degree is measured based on the distance between the individual preference values and the collective preference values (Ben-Arieh \& Easton, 2007). Dong et al. (2010) defined GCCI to measures the cardinal consensus degree of the individual PCMs in multiplicative AHP-GDM. GCCI is denoted by

$$
\operatorname{GCCI}\left(A^{(k)}\right)=\frac{2}{n(n-1)} \sum_{i<j}\left[\ln \left(a_{i j}^{(k)}\right)-\ln \left(v_{i}^{G}\right)+\ln \left(v_{j}^{G}\right)\right]^{2} \quad(k=1,2, \cdots, r),
$$

where $A^{(k)}=\left(a_{i j}^{(k)}\right)_{n \times n}$ are the individual PCMs, and $v^{G}=\left(v_{1}^{G}, v_{2}^{G}, \cdots, v_{n}^{G}\right)^{\prime}$ is the group priority vector.

\section{Geometric ordinal consensus index (GOCI) (Dong et al., 2010)}

The consensus degree is measured by comparing the positions of the alternatives between two preference vectors (Herrera-Viedma et al., 2002). Dong et al. (2010) defined GOCI measures the ordinal consensus degree of the individual PCMs in multiplicative AHP-GDM. GOCI is denoted by

$$
\operatorname{GOCI}\left(A^{(k)}\right)=\frac{1}{n} \sum_{i=1}^{n}\left|v_{i}^{(k)}-v_{i}^{G}\right|(k=1,2, \cdots, r),
$$

where $v_{i}^{(k)}$ and $v_{i}^{G}$ are the positions of the ith alternative in $v^{(k)}$ and $v^{G}$, respectively. Here, $v^{(k)}=\left(v_{1}^{(k)}, v_{2}^{(k)}, \cdots, v_{n}^{(k)}\right)^{\prime}$ is the priority vector derived from the individual PCMs $A^{(k)}=\left(a_{i j}^{(k)}\right)_{n \times n}$, and $v^{G}=\left(v_{1}^{G}, v_{2}^{G}, \cdots, v_{n}^{G}\right)^{\prime}$ is the group priority vector. 
If $\operatorname{GCCI}\left(A^{(k)}\right)=0\left(\operatorname{GOCI}\left(A^{(k)}\right)=0\right)$, then $A^{(k)}$ is of fully cardinal (ordinal) consensus. If $\operatorname{GCCI}\left(A^{(k)}\right)\left(\operatorname{GOCI}\left(A^{(k)}\right)\right)$ is less than the established threshold according to the actual situation, then $A^{(k)}$ is of the acceptable cardinal (ordinal) consensus; Otherwise, we revise $A^{(k)}$ until it reaches the acceptable cardinal (ordinal) consensus.

Note that the smaller the value of GCCI (GOCI) is, the better is the cardinal (ordinal) consensus. In actual situations, the GCCI and GOCI values of the individual PCMs should be as small as possible. Without loss of generality, we set the threshold of GCCI as 0.5 and the desired value of GOCI as zero in this study. In other words, an individual PCM has the acceptable consensus when GCCI $<0.5$ and GCCI $=0$.

Moreover, two criteria developed by Xu \& Wei (1999) to evaluate the revision effectiveness of the PCMs are introduced. Suppose that $\hat{A}=\left(\hat{a}_{i j}\right)_{n \times n}$ is the revision PCM obtained from the original PCM $A=\left(a_{i j}\right)_{n \times n}$. Let

$$
\delta=\max \left\{\left|a_{i j}-\hat{a}_{i j}\right|, i, j=1,2, \cdots, n\right\} \text { and } s=\frac{\sqrt{\sum_{j=1}^{n} \sum_{i=1}^{n}\left(a_{i j}-\hat{a}_{i j}\right)^{2}}}{n} .
$$

Both $\delta$ and $s$ express the departures of $\hat{A}$ from $A$. For a PCM structured on one to nine scale, if $\delta<2$ and $s<1$, the revision PCM is regarded as acceptable, as it preserves the most information of the original PCM (Xu \& Wei, 1999).

In order to assess the performance of the proposed TSPP, two compatibility indicators (Geometric compatibility index (GCI) and Priority violation number (PVN)) are introduced as below:

Geometric compatibility index (GCI) (Moreno-Jiménez, 2011)

GCI is the cardinal compatibility index between the group priority vector and the individual PCMs, which is defined as

$$
G C I=\sum_{k=1}^{r} \lambda_{k}\left(\frac{2}{n(n-1)} \sum_{i<j} \ln ^{2}\left(a_{i j}^{(k)} v_{j}^{G} / v_{i}^{G}\right)\right),
$$

where $\lambda_{1}, \lambda_{2}, \cdots, \lambda_{r}$ with $\sum_{k=1}^{r} \lambda_{k}=1$ and $\lambda_{k}>0(k=1,2, \cdots, r)$ are the weights of $r$ decision makers, $A^{(k)}=\left(a_{i j}^{(k)}\right)_{n \times n}(k=1,2, \cdots, r)$ are the individual PCMs, and $v^{G}=\left(v_{1}^{G}, v_{2}^{G}, \cdots, v_{n}^{G}\right)^{\prime}$ is the group priority vector.

Priority violation number (PVN) (Golany \& Kress, 1993)

$\mathrm{PVN}$ is the ordinal compatibility index denoting the number of violations in the priorities for the individual PCMs, which is defined as

$$
P V N=\sum_{k=1}^{r} \frac{2}{n(n-1)} \sum_{i<j} I_{i j}\left(A^{(k)}\right), I_{i j}\left(A^{(k)}\right)=\left\{\begin{array}{cc}
1 & \text { if } v_{i}^{G}<v_{j}^{G} \text { and } a_{i j}>1 \\
0.5 & \text { if } v_{i}^{G}=v_{j}^{G} \text { and } a_{j i} \neq 1 \\
0.5 & \text { if } v_{i}^{G} \neq v_{j}^{G} \text { and } a_{j i}=1 \\
0 & \text { otherwise }
\end{array} .\right.
$$

where $A^{(k)}(k=1,2, \cdots, r)$ are the individual PCMs, and $v^{G}=\left(v_{1}^{G}, v_{2}^{G}, \cdots, v_{n}^{G}\right)^{\prime}$ is the group priority vector.

Both GCI and PVN are employed to evaluate the compatibility between the group priority vector and the individual PCMs. The smaller the GCI and PVN values of the individual PCM are, the better is the compatibility between the judgments in the individual PCM and the group priority vector. 


\subsection{Definitions and theorems}

Definition 1 (Saaty, 1980). Matrix $A=\left(a_{i j}\right)_{n \times n}$ is called positive reciprocal matrix (PRM), if $a_{i j}>0, a_{i j}=1 / a_{j i}$ and $a_{i i}=1$ for all $i, j \in\{1,2, \cdots, n\}$.

Definition 2 (Escobar \& Moreno-Jimenez, 2000). A random variable $X(X>0)$ is reciprocal, if $X$ and $1 / X$ are identically distributed, that is, $P(X \leq x)=P(1 / X \leq x) \forall x \in R^{+}$, where $P(\cdot)$ is the probability function of $X$.

Theorem 1 (Bernardo \& Smith, 1994). If a random variable $Y(Y>0)$ follows Lognormal distribution $L N\left(\mu, \sigma^{2}\right)$, then $\operatorname{Ln}(Y)$ follows Normal distribution $N\left(\mu, \sigma^{2}\right)$.

Theorem 2 (Press, 1989). Suppose that a random variable $X$ follows Normal distribution $N\left(\theta, \sigma^{2}\right)\left(\theta\right.$ is an unknown parameter and $\sigma^{2}$ is known). Let the prior distribution $\pi(\theta)$ of $\theta$ be Normal distribution $N\left(\mu, \tau^{2}\right)$ ( $\mu$ and $\tau^{2}$ are known), then the posterior distribution $\pi(\theta \mid x)$ of $\theta$ given $x$ is Normal distribution $N\left(\mu(x), \sigma^{\prime 2}\right)$, where $\mu(x)=\frac{\tau^{2} x+\sigma^{2} \mu}{\tau^{2}+\sigma^{2}}$ and $\sigma^{\prime 2}=\frac{\tau^{2} \sigma^{2}}{\tau^{2}+\sigma^{2}}$

Remark 1. As $\mu(x)$ is the expectation of $\theta$ under the posterior distribution $\pi(\theta \mid x)$, we consider $\mu(x)$ as the Bayesian estimator of $\theta$, that is, $\hat{\theta}_{B}=\mu(x)$.

Theorem 3 (Lin et al., 2013). Suppose that $a_{i j}(1 \leq i<j \leq n)$ in a PCM $A=\left(a_{i j}\right)_{n \times n}$ are mutually independent, and follow Lognormal distribution $L N\left(v_{i} / v_{j}, \sigma^{2}\right)$. Then, the maximum likelihood estimators (MLEs) of $v_{i}$ and $\sigma^{2}$ are

$$
\hat{v}_{i}=\left(\prod_{j=1}^{n} a_{i j}\right)^{\frac{1}{n}}(i=1,2, \cdots, n) \text { and } \hat{\sigma}^{2}=\frac{1}{n(n-1)} \sum_{i \neq j}^{n}\left[\ln \left(a_{i j}\right)-\ln \left(\hat{v}_{i} / \hat{v}_{j}\right)\right]^{2} \text {. }
$$

Theorem 4 (Fichtner, 1983). A random variable $X(X>0)$ is reciprocal, if and only if $X^{a}$ $(a \neq 0)$ is reciprocal.

Theorem 5 (Escobar \& Moreno-Jimenez, 2000). Suppose that $X_{1}, X_{2}, \cdots, X_{p}$ are mutually independent random variables, and that $Y=\prod_{i=1}^{p} X_{i}$. If $X_{i}(i=1, \cdots, p)$ is a reciprocal distribution with respect to a point $c_{i}\left(c_{i}>0\right)$, then $Y$ is reciprocal distribution with respect to the point $\prod_{i=1}^{p} c_{i}$.

Theorem 6 (Press, 1989). Suppose that $X=\left(X_{1}, X_{2}, \cdots, X_{m}\right)$ is a simple sample taken from Normal distribution $N\left(\theta, \sigma^{2}\right)\left(\theta\right.$ is an unknown parameter and $\sigma^{2}$ is known), and that the prior distribution $\pi(\theta)$ of $\theta$ is Normal distribution $N\left(\mu, \tau^{2}\right)$ ( $\mu$ and $\tau^{2}$ are known), then the posterior distribution $\pi(\theta \mid X)$ of $\theta$ given $X=\left(x_{1}, x_{2}, \cdots, x_{m}\right)$ is Normal distribution $N\left(\mu_{m}(X), \sigma_{m}^{2}\right)$, where

$$
\mu_{m}(X)=\frac{m \tau^{2} \bar{x}+\sigma^{2} \mu}{m \tau^{2}+\sigma^{2}}\left(\bar{x}=\sum_{i=1}^{m} x_{i} / m\right) \text { and } \sigma_{m}^{2}=\frac{\tau^{2} \sigma^{2}}{m \tau^{2}+\sigma^{2}} .
$$

Remark 2. As $\mu_{m}(X)$ is the expectation of $\theta$ under the posterior distribution $\pi(\theta \mid X)$, we consider $\mu_{m}(X)$ as the Bayesian estimator of $\theta$, that is, $\hat{\theta}_{B}=\mu_{m}(X)$. 


\section{Two-stage prioritization procedure}

\subsection{Group decision making}

In multiplicative AHP-GDM, AIJ and AIP based on the individual PCMs are the traditional aggregation methods to determine the group priority vector.

For AIJ, first aggregate the individual judgments using weighted geometric mean method (WGMM) to obtain the group PRM $A^{G}=\left(a_{i j}^{G}\right)_{n \times n}$, where $a_{i j}^{G}=\prod_{k=1}^{r}\left(a_{i j}^{(k)}\right)^{\lambda_{k}}$, and then derive the group priority vector $v^{G}=\left(v_{1}^{G}, v_{2}^{G}, \cdots, v_{n}^{G}\right)^{\prime}$ from $A^{G}$ using certain prioritization method.

For AIP, first derive the individual priority vectors $v^{(k)}=\left(v_{1}^{(k)}, v_{2}^{(k)}, \cdots, v_{n}^{(k)}\right)^{\prime}$ from $A^{(k)}$ $(k=1,2, \cdots, r)$ using certain prioritization method, and then determine the group priority vector $v^{G}=\left(v_{1}^{G}, v_{2}^{G}, \cdots, v_{n}^{G}\right)^{\prime}$ using WGMM, where $v_{i}^{G}=\prod_{k=1}^{r}\left(v_{i}^{(k)}\right)^{\lambda_{k}} \quad(i=1,2, \cdots, n)$.

Note that AIJ and AIP are equivalent and do not violate the Pareto principle of social choice theory (Arrow, 1963) when LSSM is selected as the prioritization method (Barzilai \& Golany, 1994). However, both AIJ and AIP demand the judgments in the individual PCMs are precise and complete. In this study, the judgments in the individual PCM are not precise and are considered as random variables. Here, AIJ and AIP are not directly used to determine the group priority vector. Thus, we try to estimate the group priority vector by Bayesian approach under the condition of the acceptable consensus and consistency.

We only consider a local context with $r$ decision makers for single criterion in multiplicative AHP-GDM. Let $A^{(k)}=\left(a_{i j}^{(k)}\right)_{n \times n}(k=1,2, \cdots, r)$ be the individual PCM provided by the $k t h$ decision maker for $n$ alternatives with regards to the considered criterion, $v^{(k)}=\left(v_{1}^{(k)}, v_{2}^{(k)}, \cdots, v_{n}^{(k)}\right)^{\prime}(k=1,2, \cdots, r)$ be the individual priority vector derived from $A^{(k)}$ using certain prioritization method, and $v^{G}=\left(v_{1}^{G}, v_{2}^{G}, \cdots, v_{n}^{G}\right)^{\prime}$ be the group priority vector obtained by certain aggregation method.

In multiplicative AHP-GDM, the individual PCMs are PRMs, according to Definition 1, it follows that

$$
a_{i j}^{(k)}>0, a_{i j}^{(k)}=1 / a_{j i}^{(k)} \text { and } a_{i i}^{(k)}=1, i, j \in\{1,2, \cdots, n\}(k=1,2, \cdots, r) .
$$

The judgments in the PCM were assumed to follow Lognormal distribution that is in keeping with the reciprocity axiom of AHP theory (Escobar \& Moreno-Jimenez, 2000). Moreover, $a_{i j}^{(k)}(1 \leq i<j \leq n)$ in the individual PCM $A^{(k)}$ can be assumed to be mutually independent (Rosenbloom, 1996; Barzilai, 1997). Based on these conclusions, we assume that $a_{i j}^{(k)}(1 \leq i<j \leq n)$ follow Lognormal distribution. According to Theorem 1, it follows that $\ln \left(a_{i j}^{(k)}\right)(1 \leq i<j \leq n)$ are mutually independent and follow Normal distribution. We assume that each $\ln \left(a_{i j}^{(k)}\right) \quad(1 \leq i<j \leq n)$ follows the corresponding Normal distribution $N\left(\theta_{i j}^{(k)},\left(\sigma_{i j}^{(k)}\right)^{2}\right)$, where $\theta_{i j}^{(k)}$ and $\left(\sigma_{i j}^{(k)}\right)^{2}$ are the expectation and variance of $\ln \left(a_{i j}^{(k)}\right)$, respectively. Note that a smaller variance means greater confidence in decision makers, as the variance represents the consistency level of an individual PCM. Based on Bayesian theory, we further assume that the prior distribution $\pi\left(\theta_{i j}^{(k)}\right)$ of $\theta_{i j}^{(k)}(1 \leq i<j \leq n)$ is Normal distribution $N\left(\mu_{i j}^{(k)},\left(\tau^{(k)}\right)^{2}\right)$, where $\mu_{i j}^{(k)}$ and $\left(\tau^{(k)}\right)^{2}$ are known (Press, 1989). For the sake of simplicity, the variances of $\ln \left(a_{i j}^{(k)}\right)(1 \leq i<j \leq n)$ in the $k$ th individual PCM are assumed to 
be the same, that is, $\left(\sigma_{i j}^{(k)}\right)^{2}=\left(\sigma^{(k)}\right)^{2}(1 \leq i<j \leq n)$, and the variances of $\theta_{i j}^{(k)}$ are assumed to be the same, that is, $\left(\tau^{(k)}\right)^{2}=\tau^{2}=0.5(k=1,2, \cdots, r)$. According to Theorem 2, the posterior distribution $\pi\left(\theta_{i j}^{(k)} \mid a_{i j}^{(k)}\right)$ of $\theta_{i j}^{(k)}(1 \leq i<j \leq n)$ given $x=a_{i j}^{(k)}$ is Normal distribution $N\left(\mu_{i j}^{\prime(k)}\left(a_{i j}^{(k)}\right),\left(\sigma_{i j}^{(k) \prime}\right)^{2}\right)$, where

$$
\mu_{i j}^{\prime(k)}\left(a_{i j}^{(k)}\right)=\frac{\tau^{2} \ln \left(a_{i j}^{(k)}\right)+\left(\sigma^{(k)}\right)^{2} \mu_{i j}^{(k)}}{\tau^{2}+\left(\sigma^{(k)}\right)^{2}}(1 \leq i<j \leq n) \text { and }\left(\sigma_{i j}^{(k) \prime}\right)^{2}=\frac{\tau^{2}\left(\sigma^{(k)}\right)^{2}}{\tau^{2}+\left(\sigma^{(k)}\right)^{2}} .
$$

Note that $\left(\sigma^{(k)}\right)^{2}$ and $\mu_{i j}^{(k)}$ are determined by the corresponding MLEs derived from $A^{(k)}(k=1,2, \cdots, r)$ by Theorem 3 , that is

$$
\left(\hat{\sigma}^{(k)}\right)^{2}=\frac{1}{n(n-1)} \sum_{i \neq j}^{n}\left[\ln \left(a_{i j}^{(k)}\right)-\ln \left(\hat{v}_{i}^{(k)} / \hat{v}_{j}^{(k)}\right)\right]^{2}, \hat{\mu}_{i j}^{(k)}=\ln \left(\hat{v}_{i}^{(k)}\right)-\ln \left(\hat{v}_{j}^{(k)}\right)(1 \leq i<j \leq n),
$$

where $\hat{v}_{i}^{(k)}=\left(\prod_{j=1}^{n} a_{i j}^{(k)}\right)^{\frac{1}{n}}(i=1,2, \cdots, n)$.

From Remark 1, $\mu_{i j}^{(k)}\left(a_{i j}^{(k)}\right)$ is the Bayesian estimator of $\theta_{i j}^{(k)}$ under the posterior distribution $\pi\left(\theta_{i j}^{(k)} \mid a_{i j}^{(k)}\right)$. Thus, $\ln \left(a_{i j}^{(k)}\right)$ can be estimated by $\mu_{i j}^{\prime(k)}\left(a_{i j}^{(k)}\right)$ based on the properties of Normal distribution, that is,

$$
\ln \left(\hat{a}_{i j}^{(k)}\right)=\mu_{i j}^{\prime(k)}\left(a_{i j}^{(k)}\right)=\frac{\tau^{2} \ln \left(a_{i j}^{(k)}\right)+\left(\hat{\sigma}^{(k)}\right)^{2} \hat{\mu}_{i j}^{(k)}}{\tau^{2}+\left(\hat{\sigma}^{(k)}\right)^{2}}(1 \leq i<j \leq n) .
$$

\subsection{First stage}

In the first stage, the aim is to revise the individual PCMs without the acceptable consensus and consistency during multiplicative AHP-GDM. We first find out the individual PCMs without the acceptable consensus according to GCCI and GOCI, and then revise them till they reach the acceptable consensus. The revised individual PCMs are called individual revision PRMs. We next find out the individual PCMs and individual revision PRMs without the acceptable consistency according to $\mathrm{CR}$, and then revise them by Bayesian approach till they reach the acceptable consistency. The obtained PRMs with the acceptable consistency are called individual Bayesian revision PRMs. Finally, we obtained the revised individual PCMs with the acceptable consensus and consistency, which are called individual revision PRMs.

In order to obtain the individual revision PRMs during multiplicative AHP-GDM, Algorithm I is briefly described as follows:

Step 1. Find out the individual PCMs without the acceptable consensus according to GCCI and GOCI from the individual PCMs, and write $A^{(y)}=\left(a_{i j}^{(y)}\right)_{n \times n}(y=1,2, \cdots, c)$ (Note that the individual PCMs with the acceptable consensus are denoted by $A^{(x)}=\left(a_{i j}^{(x)}\right)_{n \times n}$ $(x=1,2, \cdots, r-c))$;

Step 2. Revise $A^{(y)}=\left(a_{i j}^{(y)}\right)_{n \times n}(y=1,2, \cdots, c)$ according to OC (The revised individual PCM is called individual revision PRM), and denote the individual revision PRMs with the acceptable consensus by $A^{\prime(y)}=\left(a_{i j}^{\prime(y)}\right)_{n \times n}(y=1,2, \cdots, c)$; 
Step 3. Find out the individual PCMs and the individual revision PRMs without the acceptable consistency according to CR from $A^{(x)}=\left(a_{i j}^{(x)}\right)_{n \times n}(x=1,2, \cdots, r-c)$ and $A^{\prime(y)}=\left(a_{i j}^{\prime(y)}\right)_{n \times n}(y=1,2, \cdots, c)$, and write $A^{(l)}=\left(a_{i j}^{(l)}\right)_{n \times n}\left(l=1,2, \cdots, r^{\prime}\right)$ (Note that the rest individual PRMs have the acceptable consensus and consistency and are denoted by $A^{(p)}=\left(a_{i j}^{(p)}\right)_{n \times n},\left(p=1,2, \cdots, r-r^{\prime}\right)$;

Step 4. Calculate the MLEs $\left(\hat{\sigma}^{(l)}\right)^{2}=\frac{1}{n(n-1)} \sum_{i \neq j}^{n}\left[\ln a_{i j}^{(l)}-\ln \left(\hat{v}_{i}^{(l)} / \hat{v}_{j}^{(l)}\right)\right]^{2}$ and $\hat{v}_{i}^{(l)}=$ $\left(\prod_{j=1}^{n} a_{i j}^{(l)}\right)^{\frac{1}{n}}$ from $A^{(l)}\left(l=1,2, \cdots, r^{\prime}\right)$ according to Theorem 3 , and calculate $\mu_{i j}^{(l)}=\ln \left(v_{i}^{(l)}\right)-\ln \left(v_{j}^{(l)}\right)(1 \leq i<j \leq n)$; $\mu_{i j}=\ln \left(v_{i}^{(l)}\right)-\ln \left(v_{j}^{(l)}\right)(1 \leq i<j \leq n) ;$
Step 5. Calculate the Bayesian estimators $\hat{\theta}_{i j}^{(l)}=\frac{\tau^{2} \ln \left(a_{i j}^{(l)}\right)+\left(\hat{\sigma}^{(l)}\right)^{2} \mu_{i j}^{(l)}}{\tau^{2}+\left(\hat{\sigma}^{(l)}\right)^{2}} \quad\left(l=1,2, \cdots, r^{\prime}\right)$,
$1 \leq i<j \leq n$ according to Theorem 2;

Step 6. Construct the transition matrices $C^{(l)}=\left(c_{i j}^{(l)}\right)_{n \times n}\left(l=1,2, \cdots, r^{\prime}\right)$, where $c_{i j}^{(l)}=\hat{\theta}_{i j}^{(l)}=\hat{\mu}_{i j}^{(l)}$ $(i<j) ; c_{i j}^{(l)}=0(i=j) ; c_{i j}^{(l)}=-\hat{\theta}_{j i}^{(l)}=-\hat{\mu}_{j i}^{(l)}(i>j)$;

Step 7. Calculate the individual Bayesian revision PRMs $A^{B(l)}=\left(a_{i j}^{B(l)}\right)_{n \times n}\left(l=1,2, \cdots, r^{\prime}\right)$, where $a_{i j}^{B(l)}=\exp \left(c_{i j}^{(l)}\right)$.

Note that if an individual Bayesian revision PRM has not the acceptable consistency, which should be revised again by Steps 4-7 of Algorithm I until it reaches the acceptable consistency. After the first stage, we obtain the individual revision PRMs with the acceptable consensus and consistency.

\subsection{Second stage}

In the second stage, the aim is to estimate the group priority vector from the new set of the individual PRMs, which consists of the individual revision PRMs and the original individual PCMs with the acceptable consensus and consistency.

The set of the individual PRMs is denoted by $\left\{A^{(K)}=\left(a_{i j}^{(K)}\right)_{n \times n}, K=1,2, \cdots, r\right\}$. The weights of $r$ decision makers are assumed to be $\lambda_{1}, \lambda_{2}, \cdots, \lambda_{r}$ with $\sum_{k=1}^{r} \lambda_{k}=1$ and $\lambda_{k}>0$ $(k=1,2, \cdots, r)$. Suppose that the group PRM $A^{G}=\left(a_{i j}^{G}\right)_{n \times n}$ is obtained using AIJ. That is, $a_{i j}^{G}=\prod_{k=1}^{r}\left(a_{i j}^{(k)}\right)^{\lambda_{k}}(i, j \in\{1,2, \cdots, n\})$. Next, assume that $a_{i j}^{(k)} \quad(k=1,2, \cdots, r)$ are mutually independent. Then, $\ln \left(a_{i j}^{(k)}\right)(k=1,2, \cdots, r)$ are mutually independent. Further, assume that $a_{i j}^{(k)}$ $(k=1,2, \cdots, r)$ follow Lognormal distribution, then $a_{i j}^{(k)}(k=1,2, \cdots, r)$ are reciprocal random variables as Lognormal distribution is also reciprocal (Escobar \& Moreno-Jimenez, 2000). According to Theorem $4,\left(a_{i j}^{(k)}\right)^{\lambda_{k}}\left(\lambda_{k} \neq 0\right)$ is a reciprocal random variable as $a_{i j}^{(k)}$ is a reciprocal random variable. According to Theorem 5, $a_{i j}^{G}=\prod_{k=1}^{r}\left(a_{i j}^{(k)}\right)^{\lambda_{k}}$ is a reciprocal random variable as $\left(a_{i j}^{(k)}\right)^{\lambda_{k}}(k=1,2, \cdots, r)$ are mutually independent and reciprocal random variables.

Based on the above facts, it is concluded that $a_{i j}^{G}=\prod_{k=1}^{r}\left(a_{i j}^{(k)}\right)^{\lambda_{k}} \quad(1 \leq i<j \leq n)$ in $A^{G}$ follow Lognormal distribution. Thus, $\ln \left(a_{i j}^{G}\right)(1 \leq i<j \leq n)$ follow Normal distribution according to Theorem 1. Without loss of generality, we assume that each $\ln \left(a_{i j}^{G}\right)(1 \leq i<j \leq n)$ 
follows Normal distribution $N\left(\theta_{i j}^{G}, \sigma^{2}\right)$, where $\sigma^{2}$ is the variance of the group PRM, and each $\theta_{i j}^{G}$ is an unknown parameter. We further assume that the prior distribution $\pi\left(\theta_{i j}^{G}\right)$ of $\theta_{i j}^{G}(1 \leq i<j \leq n)$ is Normal distribution $N\left(\mu_{i j}^{G}, \tau^{2}\right)$, where $\mu_{i j}^{G}$ and $\tau^{2}$ are known. According to Theorem 6 , the posterior distribution $\pi\left(\theta_{i j}^{G} \mid X\right)$ of $\theta_{i j}^{G}(1 \leq i<j \leq n)$ given $X=\left(a_{i j}^{(1)}, a_{i j}^{(2)}, \cdots, a_{i j}^{(r)}\right)$ is Normal distribution $N\left(\mu_{i j}^{\prime G}(X), \sigma_{1}^{2}(X)\right)$, where

$$
\mu_{i j}^{\prime G}(X)=\frac{r \tau^{2} \bar{x}_{i j}+\sigma^{2} \mu_{i j}^{G}}{r \tau^{2}+\sigma^{2}}(1 \leq i<j \leq n), \sigma_{1}^{2}(X)=\frac{\tau^{2} \sigma^{2}}{r \tau^{2}+\sigma^{2}}\left(\bar{x}_{i j}=\frac{1}{r} \sum_{k=1}^{r} \ln \left(a_{i j}^{(k)}\right)\right) .
$$

Note that $\sigma^{2}$ and $\mu_{i j}^{G}$ are determined by the MLEs derived from $A^{G}$ according to Theorem 3 , that is,

$$
\hat{\sigma}^{G}=\frac{1}{n(n-1)} \sum_{i \neq j}^{n}\left[\ln \left(a_{i j}^{(G)}\right)-\ln \left(\hat{v}_{i}^{(G)} / \hat{v}_{j}^{(G)}\right)\right]^{2}, \hat{\mu}_{i j}^{G}=\ln \left(\hat{v}_{i}^{(G)}\right)-\ln \left(\hat{v}_{j}^{(G)}\right)(1 \leq i<j \leq n),
$$

where $\hat{v}_{i}^{(G)}=\left(\prod_{j=1}^{n} a_{i j}^{(G)}\right)^{\frac{1}{n}}(i=1,2, \cdots, n)$.

From Remark 2, $\mu_{i j}^{\prime G}(X)$ is the Bayesian estimation of $\theta_{i j}^{G}$ under the posterior distribution $\pi\left(\theta_{i j}^{G} \mid X\right)$. Thus, $\ln \left(a_{i j}^{G}\right)$ is estimated by $\mu_{i j}^{\prime G}(X)$ based on the properties of Normal distribution, that is,

$$
\ln \left(\hat{a}_{i j}^{G}\right)=\mu_{i j}^{\prime G}(X)=\frac{r \tau^{2} \bar{x}_{i j}+\sigma^{2} \mu_{i j}^{G}}{r \tau^{2}+\sigma^{2}}, \bar{x}_{i j}=\frac{1}{r} \sum_{k=1}^{r} \ln \left(a_{i j}^{(k)}\right)(1 \leq i<j \leq n) .
$$

We obtain $\hat{a}_{i j}^{G}(1 \leq i<j \leq n)$ using Logarithmic inverse operation, and then set $\hat{a}_{i j}^{G}=1 / \hat{a}_{j i}^{G}$ $(1 \leq i<j \leq n)$ and $\hat{a}_{i j}^{G}=0(1 \leq i<j \leq n)$. Here, the PRM $A^{B G}=\left(\hat{a}_{i j}^{G}\right)_{n \times n}$ is called Bayesian group PRM. The priority vector derived from the Bayesian group PRM is called Bayesian group priority vector.

In order to estimate the Bayesian group priority vector in multiplicative AHP-GDM, Algorithm II is described below:

Step 1. Calculate the group PRM $A^{G}=\left(a_{i j}^{G}\right)_{n \times n}$ from the new set of the individual PRMs $A^{(K)}(K=1,2, \cdots, r)$ using AIJ, where $a_{i j}^{G}=\prod_{K=1}^{r}\left(a_{i j}^{(K)}\right)^{\lambda_{K}}$;

Step 2. Calculate the MLEs $\left(\hat{\sigma}^{G}\right)^{2}=\frac{1}{n(n-1)} \sum_{i \neq j}^{n}\left[\ln \left(a_{i j}^{(G)}\right)-\ln \left(\hat{v}_{i}^{(G)} / \hat{v}_{j}^{(G)}\right)\right]^{2} \quad$ and $\hat{v}_{i}^{(G)}=\left(\prod_{j=1}^{n} a_{i j}^{(G)}\right)^{\frac{1}{n}}(i=1,2, \cdots, n)$ from $A^{G}$ according to Theorem 3;

Step 3. Set $\mu_{i j}^{G}=\ln \left(\hat{v}_{i}^{G}\right)-\ln \left(\hat{v}_{j}^{G}\right)$ and $\bar{x}_{i j}^{G}=\frac{1}{r} \sum_{K=1}^{r} \ln \left(a_{i j}^{(K)}\right)(1 \leq i<j \leq n)$;

Step 4. Calculate the Bayesian estimators $\hat{\theta}_{i j}^{G}(x)=\mu_{i j}^{\prime G}(X)=\frac{r \tau^{2} \bar{x}_{i j}+\left(\hat{\sigma}^{G}\right)^{2} \mu_{i j}^{G}}{r \tau^{2}+\left(\hat{\sigma}^{G}\right)^{2}}$ $(1 \leq i<j \leq n)$ according to Theorem 6;

Step 5. Construct the transition matrix $C^{G}=\left(c_{i j}^{G}\right)_{n \times n}$, where $c_{i j}^{G}=\hat{\theta}_{i j}^{G}(X)=\mu_{i j}^{\prime G}(X)$ $(1 \leq i<j \leq n) ; c_{i j}^{G}=0(1 \leq i=j \leq n) ; c_{i j}^{G}=-\hat{\theta}_{j i}^{G}(X)=-\mu_{j i}^{\prime G}(X)(1 \leq j<i \leq n) ;$

Step 6. Calculate the Bayesian group PRM $A^{B G}=\left(\hat{a}_{i j}^{G}\right)_{n \times n}$, where $\hat{a}_{i j}^{G}=\exp \left(c_{i j}^{G}\right)$ for all $i, j \in\{1,2, \cdots, n\}$;

Step 7. Derive the Bayesian group priority vector $v^{B G}=\left(v_{1}^{B G}, v_{2}^{B G}, \cdots, v_{n}^{B G}\right)^{\prime}$ from $A^{B G}$ using certain prioritization method (Suggest LLSM). 
After the second stage, we obtain the Bayesian group priority vector from the Bayesian group PRM. The Bayesian group priority vector is more reliable and effective since the individual revision PCMs have the acceptable consensus and consistency as well as the most original information of the individual PCMs.

\section{Numerical examples}

In this section, we evaluate the applicability and effectiveness of the TSPP using two numerical examples and compare its performance with those of several other methods. The consensus rule is that GCCI $<0.5$ and GOCI $=0$, while Saaty rule is that $\mathrm{CR}<0.1$. For the sake of simplicity and reliability, we can assume that the weights of decision makers are equal since the individual PRMs have the acceptable consensus.

\section{Example 1}

Let us consider the group decision problem with five decisions makers taken from the reference (Dong at al., 2010). The five individual PCMs $A^{(k)}(k=1,2, \cdots, 5)$ are listed below:

$$
\begin{aligned}
A^{(1)} & =\left[\begin{array}{cccc}
1 & 4 & 6 & 7 \\
1 / 4 & 1 & 3 & 4 \\
1 / 6 & 1 / 3 & 1 & 2 \\
1 / 7 & 1 / 4 & 1 / 2 & 1
\end{array}\right], A^{(2)}=\left[\begin{array}{cccc}
1 & 5 & 7 & 9 \\
1 / 5 & 1 & 4 & 6 \\
1 / 7 & 1 / 4 & 1 & 2 \\
1 / 9 & 1 / 6 & 1 / 2 & 1
\end{array}\right], A^{(3)}=\left[\begin{array}{cccc}
1 & 3 & 5 & 8 \\
1 / 3 & 1 & 4 & 5 \\
1 / 5 & 1 / 4 & 1 & 2 \\
1 / 8 & 1 / 5 & 1 / 2 & 1
\end{array}\right], \\
A^{(4)} & =\left[\begin{array}{cccc}
1 & 4 & 5 & 6 \\
1 / 4 & 1 & 3 & 3 \\
1 / 5 & 1 / 3 & 1 & 2 \\
1 / 6 & 1 / 3 & 1 / 2 & 1
\end{array}\right], A^{(5)}=\left[\begin{array}{cccc}
1 & 1 / 2 & 1 & 2 \\
2 & 1 & 1 / 2 & 3 \\
1 & 2 & 1 & 4 \\
1 / 2 & 1 / 3 & 1 / 4 & 1
\end{array}\right] .
\end{aligned}
$$

We first investigate the consensus and consistency of the five individual PCMs. The GCCI, GOCI, and CR values of the five individual PCMs are listed in Table 1. The priority vectors and ranking orders derived from the five individual PCMs by LLSM are listed in Table 2 (The numbers within the parentheses are the ranking orders).

Table 1. GCCI, GOCI, and CR values of seven PRMs

\begin{tabular}{|c|c|c|c|c|c|c|c|}
\hline PRM & $A^{(1)}$ & $A^{(2)}$ & $A^{(3)}$ & $A^{(4)}$ & $A^{(5)}$ & $A^{\prime(5)}$ & $A^{B(5)}$ \\
\hline GCCI & 0.139 & 0.320 & 0.135 & 0.134 & 1.334 & 0.253 & 0.188 \\
\hline GOCI & 0 & 0 & 0 & 0 & 1 & 0 & 0 \\
\hline CR & 0.038 & 0.068 & 0.034 & 0.047 & 0.064 & 0.111 & 0.073 \\
\hline
\end{tabular}

Table 2. Priority vectors and ranking orders of seven PRMs under LLSM

\begin{tabular}{|c|c|c|c|c|c|c|c|}
\hline PRM & $A^{(1)}$ & $A^{(2)}$ & $A^{(3)}$ & $A^{(4)}$ & $A^{(5)}$ & $A^{\prime(5)}$ & $A^{B(5)}$ \\
\hline$v_{1}^{(k)}$ & $0.6145(1)$ & $0.6461(1)$ & $0.5693(1)$ & $0.5967(1)$ & $0.2247(3)$ & $0.6131(1)$ & $0.6131(1)$ \\
$v_{2}^{(k)}$ & $0.2246(2)$ & $0.2270(2)$ & $0.2764(2)$ & $0.2208(2)$ & $0.2958(2)$ & $0.2169(2)$ & $0.2169(2)$ \\
$v_{3}^{(k)}$ & $0.0985(3)$ & $0.0793(3)$ & $0.0967(3)$ & $0.1089(3)$ & $0.3780(1)$ & $0.1144(3)$ & $0.1144(3)$ \\
$v_{4}^{(k)}$ & $0.0624(4)$ & $0.0476(4)$ & $0.0575(4)$ & $0.0736(4)$ & $0.1015(4)$ & $0.0555(4)$ & $0.0555(4)$ \\
\hline
\end{tabular}


From Table 1, we have

$$
\begin{aligned}
& \operatorname{GCCI}\left(A^{(k)}\right)<0.5, \operatorname{GOCI}\left(A^{(k)}\right)=0, \operatorname{CR}\left(A^{(k)}\right)<0.1(k=1,2,3,4) ; \\
& \operatorname{GCCI}\left(A^{(5)}\right)>0.5, \operatorname{GOCI}\left(A^{(5)}\right)>0, \operatorname{CR}\left(A^{(5)}\right)<0.1 .
\end{aligned}
$$

It is concluded that $A^{(1)}, A^{(2)}, A^{(3)}$ and $A^{(4)}$ have the acceptable consensus and consistency, and that $A^{(5)}$ does not have the acceptable consensus even though it has the acceptable consistency. Further, it can be seen from the preference structure that $A^{(5)}$ does not have the fully ordinal consensus. More specifically, the preference structure (3214) of $A^{(5)}$ is different from the preference structure (1234) supported by the other four individual PCMs (see Table 2). Thus, $A^{(5)}$ should be adjusted till it reaches the acceptable consensus. Here, we adopt OC as the consensus tool to adjust $A^{(5)}$ for reaching the acceptable consensus. According to OC, the judgments with the highest levels of variability are $a_{12}, a_{13}, a_{14}$ and $a_{23}$ since $O C_{12}=10, O C_{13}=7$, and $O C_{23}=8$. The individual judgments $\left(a_{12}^{(5)}, a_{13}^{(5)}, a_{14}^{(5)}\right.$ and $\left.a_{23}^{(5)}\right)$ in $A^{(5)}$ disagree the most with the preference structure (1234) and should be adjusted to reach the acceptable consensus. We replace $a_{i j}^{(5)}$ with $a_{i j}^{\prime(5)}=\left(\prod_{l \neq 5} a_{i j}^{(l)}\right)^{\frac{1}{r-1}}$, so that $a_{12}^{(5)}, a_{13}^{(5)}$, $a_{14}^{(5)}$ and $a_{23}^{(5)}$. We get $a_{12}^{\prime(5)}=3.936, a_{13}^{\prime(5)}=5.692, a_{14}^{\prime(5)}=7.416$, and $a_{23}^{\prime(5)}=3.464$. Accordingly, $a_{21}^{\prime(5)}=0.254, a_{31}^{\prime(5)}=0.176, a_{41}^{\prime(5)}=0.135$, and $a_{32}^{\prime(5)}=0.289$. As a result, the individual revision PRM $A^{\prime(5)}$ is listed below. Moreover, as mentioned previously, the GCCI, GOCI and CR values of $A^{\prime(5)}$ are listed in Table 1 . The priority vector and the ranking order derived from $A^{\prime(5)}$ using LLSM are shown in Table 2.

$$
A^{\prime(5)}=\left[\begin{array}{cccc}
1 & 3.963 & 5.692 & 7.416 \\
0.254 & 1 & 3.464 & 3 \\
0.176 & 0.289 & 1 & 4 \\
0.135 & 1 / 3 & 1 / 4 & 1
\end{array}\right], A^{B(5)}=\left[\begin{array}{cccc}
1.000 & 3.720 & 5.628 & 7.989 \\
0.269 & 1.000 & 3.095 & 3.152 \\
0.178 & 0.323 & 1.000 & 3.534 \\
0.125 & 0.317 & 0.283 & 1.000
\end{array}\right] .
$$

From Table 1, we have

$$
\operatorname{GCCI}\left(A^{\prime(5)}\right)<0.5, \operatorname{GOCI}\left(A^{\prime(5)}\right)=0, \operatorname{CR}\left(A^{\prime(5)}\right)>0.1 \text {. }
$$

It is concluded that the individual revision matrix $A^{\prime(5)}$ has not the acceptable consistency even though it reaches the acceptable consensus. Thus, we next revise $A^{\prime(5)}$ using Steps 4-7 of Algorithm I until it reaches the acceptable consistency. The individual Bayesian revision PRM $A^{B(5)}$ is listed above. Moreover, the GCCI, GOCI, and CR values of $A^{B(5)}$ are listed in Table 1 . Finally, the priority vector and the ranking order derived from $A^{B(5)}$ using LLSM are shown in Table 2.

From Table 1, we have

$$
\operatorname{GCCI}\left(A^{B(5)}\right)<0.5, \operatorname{GOCI}\left(A^{B(5)}\right)=0, C R\left(A^{B(5)}\right)<0.1 \text {. }
$$

That is, the individual Bayesian revision PRM $A^{B(5)}$ is have the acceptable consensus and consistency.

The new set of the individual PRMs consists of four original individual PCMs $\left(A^{(1)}, A^{(2)}\right.$ , $A^{(3)}$ and $A^{(4)}$ ) and one individual Bayesian revision PRM $\left(A^{B(5)}\right)$, which have the acceptable consensus and consistency (GCCI $<0.5, \mathrm{GOCI}=0, \mathrm{CR}<0.1)$. 
We next estimate the Bayesian group priority vector using Algorithm II for the new set of the individual PRMs. The Bayesian group PRM $\left(A^{B G}\right)$ and the Bayesian group priority vector derived from $A^{B G}$ by LLSM are given as follow:

$$
A^{B G}=\left[\begin{array}{llll}
1.000 & 3.844 & 5.694 & 7.602 \\
0.260 & 1.000 & 3.349 & 4.079 \\
0.176 & 0.299 & 1.000 & 2.221 \\
0.132 & 0.245 & 0.450 & 1.000
\end{array}\right], v^{B G}=(0.6092,0.2329,0.0991,0589)^{\prime} .
$$

Moreover, the group PRM $\left(A^{G}\right)$ obtained from the original individual PCMs using AIJ and the group priority vector derived from $A^{G}$ by LLSM are as follow:

$$
A^{G}=\left[\begin{array}{llll}
1.000 & 2.605 & 4.020 & 5.706 \\
0.384 & 1.000 & 2.352 & 4.043 \\
0.249 & 0.425 & 1.000 & 2.297 \\
0.175 & 0.247 & 0.435 & 1.000
\end{array}\right], v^{G}=(0.5311,0.2640,0.1341,0708)^{\prime}
$$

From the viewpoint of revision effectiveness, we have

$$
\delta\left(A^{B G}, A^{G}\right)=1.896<2, s\left(A^{B G}, A^{G}\right)=0.749<1 .
$$

Thus, the Bayesian group PRM $\left(A^{B G}\right)$ is acceptable as it preserves the most original information of the group PRM $\left(A^{G}\right)$ obtained from the individual PCMs.

Finally, we compare TSPP with AIP, AIJ and row geometric mean method (RGMM) (Dong et al., 2010) based on the compatibility indicators (GCI and PVN). Note that we take EM as the prioritization method in AIJ and AIP since AIJ and AIP is equivalent when selecting LSSM as prioritization method (Barzilai \& Golany, 1994). The group priority vectors and ranking orders obtained by AIJ, AIP, RGMM and TSPP are listed in Table 3. The compatibility indicators (GCI and PVN) between the individual PCMs and the group priority vectors obtained using AIJ, AIP, RGMM and TSPP are listed in Table 4.

Table 3. Group priority vectors and ranking orders obtained by AIJ, AIP, RGMM and TSPP

\begin{tabular}{|c|c|c|c|c|}
\hline Aggregation method & AIJ (EM) & AIP (EM) & RGMM & TSPP \\
\hline$v_{1}^{G}$ & $0.5324(1)$ & $0.5344(1)$ & $0.5416(1)$ & $\mathbf{0 . 6 0 9 2 ( 1 )}$ \\
$v_{2}^{G}$ & $0.2634(2)$ & $0.2637(2)$ & $0.2579(2)$ & $\mathbf{0 . 2 3 2 9}(2)$ \\
$v_{3}^{G}$ & $0.1333(3)$ & $0.1326(3)$ & $0.1299(3)$ & $\mathbf{0 . 0 9 9 1 ( 3 )}$ \\
$v_{4}^{G}$ & $0.0709(4)$ & $0.0694(4)$ & $0.0688(4)$ & $\mathbf{0 . 0 5 8 9 ( 4 )}$ \\
\hline
\end{tabular}

Table 4. GCI and PVN values for AIJ, AIJ, RGMM and TSPP

\begin{tabular}{|c|c|c|c|c|}
\hline Aggregation method & AIJ(EM) & AIP(EM) & RGMM & TSPP \\
\hline GCI & 0.391 & 0.415 & 0.341 & $\mathbf{0 . 1 0 0}$ \\
\hline PVN & 0.083 & 0.083 & 0.083 & $\mathbf{0 . 0 8 3}$ \\
\hline
\end{tabular}

From Tables 2 and 3, the group ranking order obtained using TSPP is the same as those derived from the new set of the individual PRMs. In other words, the TSPP does not violate the Pareto principle of social choice theory in the case of Example 1. Further, it can be seen 
from Table 3 that the group ranking orders obtained by TSPP, AIJ, AIP and RGMM are the same, that is, the TSPP does not result in the rank order reversal. From Table 4 shows that the GCI and PVN values of the TSPP are not higher than the corresponding ones of AIJ, AIP and RGMM. With respect to the ordinal and cardinal compatibilities, the results of the TSPP are more reliable than those of AIJ, AIP and RGMM.

\section{Example 2}

Let us consider another group decision analysis situation with six decision makers taken from the reference (Altuzarra et al., 2007). In this case, the six individual PCMs $A^{(k)}(k=1,2, \cdots, 6)$ are listed below:

$$
\begin{aligned}
A^{(1)} & =\left[\begin{array}{ccccc}
1 & 3 & 5 & 4 & 7 \\
1 / 3 & 1 & 3 & 2 & 5 \\
1 / 5 & 1 / 3 & 1 & 1 / 2 & 3 \\
1 / 4 & 1 / 2 & 2 & 1 & 3 \\
1 / 7 & 1 / 5 & 1 / 3 & 1 / 3 & 1
\end{array}\right], A^{(2)}=\left[\begin{array}{ccccc}
1 & 4 & 3 & 5 & 8 \\
1 / 4 & 1 & 4 & 3 & 6 \\
1 / 3 & 1 / 4 & 1 & 1 & 5 \\
1 / 5 & 1 / 3 & 1 & 1 & 7 \\
1 / 8 & 1 / 6 & 1 / 5 & 1 / 7 & 1
\end{array}\right], \\
A^{(3)} & =\left[\begin{array}{ccccc}
1 & 1 / 2 & 3 & 2 & 5 \\
2 & 1 & 5 & 1 & 2 \\
1 / 3 & 1 / 5 & 1 & 2 & 1 / 2 \\
1 / 2 & 1 & 1 / 2 & 1 & 5 \\
1 / 5 & 1 / 2 & 2 & 1 / 5 & 1
\end{array}\right], A^{(4)}=\left[\begin{array}{ccccc}
1 & 3 & 5 & 2 & 6 \\
1 / 3 & 1 & 1 & 3 & 2 \\
1 / 5 & 1 & 1 & 4 & 5 \\
1 / 2 & 1 / 3 & 1 / 4 & 1 & 1 / 2 \\
1 / 6 & 1 / 2 & 1 / 5 & 2 & 1
\end{array}\right], \\
A^{(5)} & =\left[\begin{array}{ccccc}
1 & 2 & 6 & 3 & 3 \\
1 / 2 & 1 & 2 & 5 & 4 \\
1 / 6 & 1 / 2 & 1 & 1 / 2 & 1 \\
1 / 3 & 1 / 5 & 2 & 1 & 5 \\
1 / 3 & 1 / 4 & 1 & 1 / 5 & 1
\end{array}\right], A^{(6)}=\left[\begin{array}{ccccc}
1 & 2 & 5 & 4 & 9 \\
1 / 2 & 1 & 3 & 2 & 6 \\
1 / 5 & 1 / 3 & 1 & 1 & 2 \\
1 / 4 & 1 / 2 & 1 & 1 & 3 \\
1 / 9 & 1 / 6 & 1 / 2 & 1 / 3 & 1
\end{array}\right] .
\end{aligned}
$$

We first investigate the consensus and consistency of the six individual PCMs. The GCCI, GOCI and CR values of the six individual PCMs are listed in Table 5. The priority vectors and the ranking orders derived from the six individual PCMs by LLSM are listed in Table 6.

Table 5. CR, GCCI, and GOCI values of six individual PCMs

\begin{tabular}{|c|c|c|c|c|c|c|}
\hline PCM & $A^{(1)}$ & $A^{(2)}$ & $A^{(3)}$ & $A^{(4)}$ & $A^{(5)}$ & $A^{(6)}$ \\
\hline GCCI & 0.113 & 0.378 & 0.693 & 0.752 & 0.338 & 0.045 \\
\hline GOCI & 0 & 0 & 0.4 & 0.8 & 0 & 0 \\
\hline CR & 0.028 & 0.100 & 0.227 & 0.147 & 0.123 & 0.005 \\
\hline
\end{tabular}

Table 6. Priority vectors and ranking orders of six individual PCMs under LLSM

\begin{tabular}{|c|c|c|c|c|c|c|}
\hline PCM & $A^{(1)}$ & $A^{(2)}$ & $A^{(3)}$ & $A^{(4)}$ & $A^{(5)}$ & $A^{(6)}$ \\
\hline$v_{1}^{(k)}$ & $0.491(1)$ & $0.470(1)$ & $0.309(2)$ & $0.451(1)$ & $0.407(1)$ & $0.475(1)$ \\
$v_{2}^{(k)}$ & $0.232(2)$ & $0.244(2)$ & $0.327(1)$ & $0.183(3)$ & $0.291(2)$ & $0.261(2)$ \\
$v_{3}^{(k)}$ & $0.092(4)$ & $0.115(4)$ & $0.105(4)$ & $0.211(2)$ & $0.085(4)$ & $0.098(4)$ \\
$v_{4}^{(k)}$ & $0.138(3)$ & $0.141(3)$ & $0.188(3)$ & $0.074(4)$ & $0.147(3)$ & $0.120(3)$ \\
$v_{5}^{(k)}$ & $0.046(5)$ & $0.141(5)$ & $0.072(5)$ & $0.081(5)$ & $0.070(5)$ & $0.046(5)$ \\
\hline
\end{tabular}


From Table 5, we have

$$
\begin{aligned}
& \operatorname{GCCI}\left(A^{(4)}\right)>\operatorname{GCCI}\left(A^{(3)}\right)>0.5, \operatorname{GOCI}\left(A^{(4)}\right)>\operatorname{GOCI}\left(A^{(3)}\right)>0 ; \\
& \operatorname{CR}\left(A^{(6)}\right)<\operatorname{CR}\left(A^{(1)}\right)<0.1<\operatorname{CR}\left(A^{(2)}\right)<C R\left(A^{(5)}\right)<C R\left(A^{(4)}\right)<C R\left(A^{(3)}\right) .
\end{aligned}
$$

It is concluded that $A^{(3)}$ and $A^{(4)}$ have not the acceptable consensus while $A^{(1)}, A^{(2)}$, $A^{(5)}$ and $A^{(6)}$ have the acceptable consensus. Moreover, $A^{(2)}, A^{(3)}, A^{(4)}$ and $A^{(5)}$ have not the acceptable consistency while $A^{(1)}$ and $A^{(6)}$ have the acceptable consistency. From the preference structure, $A^{(3)}$ and $A^{(4)}$ are not of the fully ordinal consensus. More specifically, the preference structures of $A^{(3)}$ and $A^{(4)}$ are (21435) and (12354), respectively, which are in disagreement with the preference structure (12435) supported by the other four individual PCMs (see Table 6). Thus, $A^{(3)}$ and $A^{(4)}$ should be adjusted till they reach the acceptable consensus. Here, we adopt OC as the consensus tool to adjust $A^{(3)}$ and $A^{(4)}$. According to OC, the judgments with the highest level of variability are $a_{12}, a_{34}, a_{35}$ and $a_{45}$ since $O C_{12}=8, O C_{34}=8, O C_{35}=10$, and $O C_{45}=14$. Moreover, the judgments $\left(a_{12}^{(3)}, a_{35}^{(3)}, a_{34}^{(4)}\right.$ and $\left.a_{45}^{(4)}\right)$ in $A^{(3)}$ and $A^{(4)}$ disagree the most with the preference structure (12435) and should be adjusted to reach the acceptable consensus. We replace $a_{i j}^{(k)}$ with $a_{i j}^{\prime(k)}=\left(\prod_{l \neq k} a_{i j}^{(l)}\right)^{\frac{1}{r-1}}(k=3,4)$ for $a_{12}^{(3)}, a_{35}^{(3)}, a_{34}^{(4)}$ and $a_{45}^{(4)}$ in $A^{(3)}$ and $A^{(4)}$ for reaching the acceptable consensus. Thus, $a_{12}^{\prime(3)}=2.702, a_{35}^{\prime(3)}=2.724, a_{34}^{\prime(4)}=0.871$, and $a_{45}^{\prime(4)}=4.360$. Accordingly, $a_{21}^{\prime(3)}=0.370, a_{53}^{\prime(3)}=0.367, a_{43}^{\prime(4)}=1.149$, and $a_{54}^{\prime(4)}=0.229$. The two individual revision matrices $\left(A^{\prime(3)}\right.$ and $\left.A^{\prime(4)}\right)$ for $A^{(3)}$ and $A^{(4)}$ are listed below. Moreover, the GCCI, GOCI and CR values of $A^{\prime(3)}$ and $A^{\prime(4)}$ are shown in Table 7 . The priority vectors and the ranking orders derived from $A^{(3)}$ and $A^{(4)}$ by LLSM are given in Table 8.

$$
A^{\prime(3)}=\left[\begin{array}{ccccc}
1 & 2.702 & 3 & 2 & 5 \\
0.370 & 1 & 5 & 1 & 2 \\
1 / 3 & 1 / 5 & 1 & 2 & 2.724 \\
1 / 2 & 1 & 1 / 2 & 1 & 5 \\
1 / 5 & 1 / 2 & 0.367 & 1 / 5 & 1
\end{array}\right], A^{\prime(4)}=\left[\begin{array}{ccccc}
1 & 3 & 5 & 2 & 6 \\
1 / 3 & 1 & 1 & 3 & 2 \\
1 / 5 & 1 & 1 & 0.871 & 5 \\
1 / 2 & 1 / 3 & 1.149 & 1 & 4.360 \\
1 / 6 & 1 / 2 & 1 / 5 & 0.229 & 1
\end{array}\right] .
$$

From Table 7, we have

$$
\begin{aligned}
& \operatorname{GCCI}\left(A^{\prime(3)}\right)<0.5, \operatorname{GOCI}\left(A^{\prime(3)}\right)=0, \operatorname{CR}\left(A^{\prime(3)}\right)>0.1 ; \\
& \operatorname{GCCI}\left(A^{\prime(4)}\right)<0.5, \operatorname{GOCI}\left(A^{\prime(4)}\right)>0, \operatorname{CR}\left(A^{\prime(4)}\right)>0.1 .
\end{aligned}
$$

It is concluded that $A^{\prime(3)}$ and $A^{\prime(4)}$ have not the acceptable consistency even though they have the acceptable cardinal consensus. We next revise $A^{\prime(3)}, A^{\prime(4)}, A^{(2)}$ and $A^{(5)}$ using Steps 4-7 of Algorithm I till they reach the acceptable consistency. The four individual Bayesian revision matrices $\left(A^{B(3)}, A^{B(4)}, A^{B(2)}\right.$ and $\left.A^{B(5)}\right)$ corresponding to $A^{\prime(3)}, A^{\prime(4)}, A^{(2)}$ and $A^{(5)}$, respectively, are listed below. Moreover, the GCCI, GOCI and CR values of $A^{B(3)}$, $A^{B(4)}, A^{B(2)}$ and $A^{B(5)}$ are shown in Table 7 . The priority vectors and the ranking orders derived from $A^{B(3)}, A^{B(4)}, A^{B(2)}$ and $A^{B(5)}$ by LLSM are shown in Table 8. Furthermore, in the case of $A^{B(4)}$, the distance between $0.165(3)$ and $0.164(4)$ is 0.001 (very small) (see Table 8 ), thus the rank orders ((3) and (4)) may be exchanged by coordination. This makes the GOCI value of $A^{B(4)}$ equal to zero. 


$$
\begin{aligned}
A^{B(3)}= & {\left[\begin{array}{lllll}
1.000 & 1.327 & 2.980 & 2.112 & 5.514 \\
0.428 & 1.000 & 3.209 & 1.088 & 2.476 \\
0.336 & 0.312 & 1.000 & 1.390 & 2.500 \\
0.473 & 0.919 & 0.720 & 1.000 & 3.991 \\
0.181 & 0.404 & 0.400 & 0.251 & 1.000
\end{array}\right], A^{B(4)}=\left[\begin{array}{llllll}
1.000 & 1.468 & 4.223 & 2.252 & 6.711 \\
0.355 & 1.000 & 1.053 & 2.251 & 2.379 \\
0.237 & 0.950 & 1.000 & 0.911 & 4.249 \\
0.444 & 0.444 & 1.097 & 1.000 & 3.856 \\
0.149 & 0.420 & 0.235 & 0.259 & 1.000
\end{array}\right], } \\
A^{B(2)}= & {\left[\begin{array}{llllll}
1.000 & 1.532 & 3.296 & 4.675 & 9.709 \\
0.312 & 1.000 & 3.304 & 2.684 & 6.513 \\
0.303 & 0.303 & 1.000 & 0.993 & 4.568 \\
0.214 & 0.373 & 1.007 & 1.000 & 5.816 \\
0.103 & 0.154 & 0.219 & 0.172 & 1.000
\end{array}\right], A^{B(5)}=\left[\begin{array}{lllll}
1.000 & 1.206 & 5.567 & 2.918 & 3.752 \\
0.564 & 1.000 & 2.405 & 3.643 & 4.043 \\
0.180 & 0.416 & 1.000 & 0.524 & 1.064 \\
0.343 & 0.274 & 1.908 & 1.000 & 3.716 \\
0.267 & 0.247 & 0.939 & 0.269 & 1.000
\end{array}\right] . }
\end{aligned}
$$

Table 7. CR, GCCI, and GOCI values of six PRMs

\begin{tabular}{|c|c|c|c|c|c|c|}
\hline PRM & $A^{\prime(3)}$ & $A^{B(3)}$ & $A^{\prime(4)}$ & $A^{B(4)}$ & $A^{B(2)}$ & $A^{B(5)}$ \\
\hline CR & 0.156 & 0.030 & 0.105 & 0.023 & 0.006 & 0.033 \\
\hline GCCI & 0.391 & 0.190 & 0.353 & 0.211 & 0.228 & 0.204 \\
\hline GOCI & 0 & 0 & 0.400 & $0.400(0)$ & 0 & 0 \\
\hline
\end{tabular}

Table 8. Priority vectors and ranking orders of six PRMs under LLSM

\begin{tabular}{|c|c|c|c|c|c|c|}
\hline PRM & $A^{B(2)}$ & $A^{B(5)}$ & $A^{\prime(3)}$ & $A^{B(3)}$ & $A^{\prime(4)}$ & $A^{B(4)}$ \\
\hline$v_{1}^{(k)}$ & $0.444(1)$ & $0.389(1)$ & $0.405(1)$ & $0.378(1)$ & $0.453(1)$ & $0.425(1)$ \\
$v_{2}^{(k)}$ & $0.267(2)$ & $0.300(2)$ & $0.219(2)$ & $0.228(2)$ & $0.184(2)$ & $0.195(2)$ \\
$v_{3}^{(k)}$ & $0.126(4)$ & $0.087(4)$ & $0.137(4)$ & $0.144(4)$ & $0.156(3)$ & $\mathbf{0 . 1 6 5 ( 3 )}$ \\
$v_{4}^{(k)}$ & $0.129(3)$ & $0.152(3)$ & $0.176(3)$ & $0.184(3)$ & $0.155(4)$ & $\mathbf{0 . 1 6 4 ( 4 )}$ \\
$v_{5}^{(k)}$ & $0.034(5)$ & $0.083(5)$ & $0.063(5)$ & $0.066(5)$ & $0.053(5)$ & $0.056(5)$ \\
\hline
\end{tabular}

From Table 7, we have

$$
\operatorname{GCCI}\left(A^{B(k)}\right)<0.5, \operatorname{GOCI}\left(A^{B(k)}\right)=0, C R\left(A^{B(k)}\right)<0.1(k=2,3,4,5) .
$$

That is, $A^{B(3)}, A^{B(4)}, A^{B(2)}$ and $A^{B(5)}$ have the acceptable consensus and consistency. At the same time, $A^{(1)}$ and $A^{(6)}$ have the acceptable consensus and consistency.

Table 9. CR, GCCI and GOCI values of six PRMs

\begin{tabular}{|c|c|c|c|c|c|c|}
\hline PRM & $A^{(1)}$ & $A^{B(2)}$ & $A^{B(3)}$ & $A^{B(4)}$ & $A^{B(5)}$ & $A^{(6)}$ \\
\hline GCCI & 0.133 & 0.228 & 0.190 & 0.211 & 0.204 & 0.045 \\
\hline GOCI & 0 & 0 & 0 & 0 & 0 & 0 \\
\hline CR & 0.028 & 0.006 & 0.030 & 0.023 & 0.033 & 0.005 \\
\hline
\end{tabular}

The new set of the individual PRMs consists of two original individual PCMs $\left(A^{(1)}\right.$ and $\left.A^{(6)}\right)$ and four of the individual Bayesian revision matrices $\left(A^{B(2)}, A^{B(3)}, A^{B(4)}\right.$ and $\left.A^{B(5)}\right)$, which are the acceptable consensus and consistency (GCCI $<0.5$, GOCI $=0, \mathrm{CR}<0.1$ ) (See Table 9). 
We next obtain the Bayesian group priority vector for the new set of the individual PRMs using Algorithm II. The Bayesian group PRM $\left(A^{B G}\right)$ obtained from the new set of the individual PRMs and the Bayesian group priority vector derived from $A^{B G}$ by LLSM are given as follow:

$$
A^{B G}=\left[\begin{array}{lllll}
1.000 & 1.656 & 4.129 & 3.264 & 6.167 \\
0.500 & 1.000 & 2.543 & 2.284 & 4.035 \\
0.242 & 0.393 & 1.000 & 0.999 & 2.090 \\
0.306 & 0.438 & 1.001 & 1.000 & 2.702 \\
0.162 & 0.248 & 0.478 & 0.370 & 1.000
\end{array}\right], v^{B G}=(0.430,0.263,0.116,0.131,0.060)^{\prime} .
$$

The group PRM $\left(A^{G}\right)$ obtained from the original individual PRMs using AIJ and the group priority vector derived from $A^{G}$ by LLSM are shown below:

$$
A^{G}=\left[\begin{array}{lllll}
1.000 & 2.040 & 4.347 & 3.141 & 5.972 \\
0.490 & 1.000 & 2.667 & 2.376 & 3.772 \\
0.230 & 0.375 & 1.000 & 1.122 & 2.054 \\
0.318 & 0.421 & 0.891 & 1.000 & 3.039 \\
0.167 & 0.265 & 0.487 & 0.329 & 1.000
\end{array}\right], v^{G}=(0.439,0.258,0.114,0.129,0.059)^{\prime}
$$

From the viewpoint of revision effectiveness, we have

$$
\delta\left(A^{B G}, A^{G}\right)=0.384<<2, s\left(A^{B G}, A^{G}\right)=0.139<<1 .
$$

That is to say, the Bayesian group PRM $\left(A^{B G}\right)$ is acceptable, as it preserves the most original information of the group PRM $\left(A^{G}\right)$ obtained from the individual PCMs.

Finally, we compare TSPP with AIP, AIJ and BPP (Altuzarra et al., 2007) based on the compatibility indicators (GCI and PVN). Note that we also use EM as the prioritization method in AIJ and AIP. The group priority vectors and the ranking orders obtained by AIJ, AIP, BPP and TSPP are listed in Table 10. The compatibility indicators (GCI and PVN) between the individual PCMs and the group priority vectors obtained by AIJ, AIP, BPP and TSPP are listed in Table 11.

Table 10. Group priority vectors and ranking orders obtained by AIJ, AIP, BPP and TSPP

\begin{tabular}{|c|c|c|c|c|}
\hline Aggregation method & AIJ(EM) & AIP(EM) & BPP & TSPP \\
\hline$v_{1}^{G}$ & $0.438(1)$ & $0.436(1)$ & $0.479(1)$ & $\mathbf{0 . 4 3 0}(\mathbf{1})$ \\
$v_{2}^{G}$ & $0.258(2)$ & $0.256(2)$ & $0.259(2)$ & $\mathbf{0 . 2 6 3 ( 2 )}$ \\
$v_{3}^{G}$ & $0.114(4)$ & $0.116(4)$ & $0.097(4)$ & $\mathbf{0 . 1 1 6 ( 4 )}$ \\
$v_{4}^{G}$ & $0.130(3)$ & $0.133(3)$ & $0.119(3)$ & $\mathbf{0 . 1 3 1 ( 3 )}$ \\
$v_{5}^{G}$ & $0.059(5)$ & $0.059(5)$ & $0.045(5)$ & $\mathbf{0 . 0 6 0 ( 5 )}$ \\
\hline
\end{tabular}

Table 11. GCI and PVN values of AIJ, AIP, BPP and TSPP

\begin{tabular}{|c|c|c|c|c|}
\hline Aggregation method & AIJ(EM) & AIP(EM) & BPP & TSPP \\
\hline GCI & 0.387 & 0.387 & 0.363 & $\mathbf{0 . 2 7 2}$ \\
\hline PVN & 0.108 & 0.108 & 0.108 & $\mathbf{0 . 1 0 8}$ \\
\hline
\end{tabular}


From Tables 6, 8 and 10, it is clear that each ranking order derived from the new set of the individual PRMs is the same as the group one obtained using TSPP. In other words, the TSPP does not violate the Pareto principle of social choice theory in the case of Example 2. Table 10 shows that the ranking order obtained using TSPP is same to those obtained using AIJ, AIP and BPP. That is to say, the TSPP does not result in rank order reversal. From Table 11 , it can be seen that the GCI and PVN values of the TSPP are not higher than the corresponding ones of AIJ, AIP and BPP. With respect to the ordinal and cardinal compatibilities, the results for the TSPP are more reliable than those of RGMM, AIP and AIJ.

The above examples highlight the performance of the TSPP during multiplicative AHPGDM with respect to two measure indices (GCI and PVN) and two criteria for revision effectiveness. The results clearly show that the individual revision PRM has better consensus and consistency than the corresponding individual PCM, and that the Bayesian group PRM preserves the most original information of the group PRM obtained from the individual PRMs. Moreover, the TSPP satisfies the Pareto principle of social choice theory and does not result in a reversal of the rank order.

However, the TSPP demands that the individual PCMs are constructed on one to nine scale, and that the multiplicative preference relations are complete. We now are not sure if the TSPP can be extended to the incomplete PCMs and other preference relations such as fuzzy preference and fuzzy linguistic preference, which is our research direction in the future.

\section{Conclusions}

In this study, two-stage prioritization procedure (TSPP) is proposed to determine the group priority vector for multiplicative AHP-GDM. The TSPP first checks and revises the individual PCMs for reaching the acceptable consensus and consistency, and then estimates the group priority vector using Bayesian approach. The results obtained for two different numerical examples confirm that the TSPP is effective in improving the consistency and consensus of the individual PCMs and yields more accurate group priority vector. Further, the TSPP does not violate the Pareto principle of social choice theory and to some degree performs better than some of other methods, as evidenced by comparisons based on measure indices and criteria for revision effectiveness. Thus, the TSPP is an effective alternative for resolving highly complex GDM-related problems. In the future, we aim to extend the TSPP to the incomplete individual PCMs and other preference relations during large-scale AHP-GDM.

\section{Acknowledgements}

This research has been partially supported by grants from Humanities and Social Science Program of Ministry of Education of China (\#17YJA630051) and grants from the National Natural Science Foundation of China (\#U1811462, \#71725001, and \#71910107002). 


\section{References}

Abdullah, S. M., Siddiqua, S., Siddiquee, M. S. H., \& Hossain, N. (2017). Modeling and forecasting exchange rate volatility in Bangladesh using GARCH models: a comparison based on normal and Student's t-error distribution. Financial Innovation, 3, 18. https://doi.org/10.1186/s40854-017-0071-z

Altuzarra, A., Moreno-Jiménez, J. M., \& Salvador, M. (2007). A Bayesian priorization procedure for AHP-group decision making. European Journal of Operational Research, 182(1), 367-382. https://doi.org/10.1016/j.ejor.2006.07.025

Altuzarra, A., Moreno-Jiménez, J. M., \& Salvador, M. (2010). Consensus building in AHP-group decision making, a Bayesian approach. Operations Research, 58(6), 1755-1773. https://doi.org/10.1287/opre.1100.0856

Arrow, K. J. (1963). Social choice and individual values (2 ed.). Wiley.

Barzilai, J., Cook, W. D., \& Golany, B. (1987). Consistent weights for judgments matrices of the relative importance of alternatives. Operations Research Letters, 6(3), 131-134. https://doi.org/10.1016/0167-6377(87)90026-5

Barzilai, J., \& Golany, B. (1994). AHP rank reversal normalization and aggregation rules. INFOR, 32(2), 57-64. https://doi.org/10.1080/03155986.1994.11732238

Barzilai, J. (1997). Deriving weights from pairwise comparison matrices. Journal of the Operational Research Society, 48(12), 1226-1232. https://doi.org/10.1057/palgrave.jors.2600474

Barfod, M. B., Honert, R. V. D., \& Salling, K. B. (2016). Modeling group perceptions using stochastic simulation, scaling issues in the multiplicative AHP. International Journal of Information Technology \& Decision Making, 15(2), 453-474. https://doi.org/10.1142/S0219622016500103

Basak, I. (1990). Testing for the rank ordering of the priorities of the alternatives in Saaty's ratio-scale method. European Journal of Operational Research, 48(1), 148-152. https://doi.org/10.1016/0377-2217(90)90071-I

Basak, I. (1998). Probabilistic judgments specified partially in the analytic hierarchy process. European Journal of Operational Research, 108(1), 153-164. https://doi.org/10.1016/S0377-2217(97)00140-9

Basak, I. (2001). The categorical data analysis approach for ratio model of pairwise comparisons. European Journal of Operation Research, 128(3), 532-544. https://doi.org/10.1016/S0377-2217(99)00372-0

Bernardo, J. M. \& Smith, A. F. M. (1994). Bayesian theory. Wiley. https://doi.org/10.1002/9780470316870

Ben-Arieh, D., \& Easton, T. (2007). Multi-criteria group consensus under linear cost opinion elasticity. Decision Support Systems, 43(3), 713-721. https://doi.org/10.1016/j.dss.2006.11.009

Crawford, G., \& Williams, C. (1985). A note on the analysis of subjective judgment matrices. Journal of Mathematical Psychology, 29(4), 387-405. https://doi.org/10.1016/0022-2496(85)90002-1

Dong, Y., Xu, Y., Li, H., \& Dai, M. (2008). A comparative study of the numerical scales and the prioritization methods in AHP. European Journal of Operational Research, 186(1), 229-242. https://doi.org/10.1016/j.ejor.2007.01.044

Dong, Y., Zhang, G., Hong, W. C., \& Xu, Y. (2010). Consensus models for AHP group decision making under row geometric mean prioritization method. Decision Support Systems, 49(3), 281-289. https://doi.org/10.1016/j.dss.2010.03.003

Dong, Q., \& Saaty, T. L. (2014). An analytic hierarchy process model of group consensus. Journal of Systems Science and Systems Engineering, 23(3), 362-374. https://doi.org/10.1007/s11518-014-5247-8

Dong, Y., Li, C., Chiclana, F., \& Herrera-Viedma, E. (2016). Average-case consistency measurement and analysis of interval-valued reciprocal preference relations. Knowledge-Based Systems, 114, 108-117. https://doi.org/10.1016/j.knosys.2016.10.005 
Escobar, M. T, \& Moreno-Jiménez, J. M. (2000). Reciprocal distributions in the analytic hierarchy process. European Journal of Operational Research, 123(1), 154-174. https://doi.org/10.1016/S0377-2217(99)00086-7

Fichtner, J. (1983). Some thoughts about the mathematics of the analytic hierarchy process. Hochschule der Bundeswehr.

Forman, E., \& Peniwati, K. (1998). Aggregating individual judgments and priorities with the analytic hierarchy process. European Journal of Operational Research, 108(1), 165-169. https://doi.org/10.1016/S0377-2217(97)00244-0

Gargallo, P., Moreno-Jiménez, J. M., \& Salvador, M. (2007). AHP-group decision making, a Bayesian approach based on mixtures for group pattern identification. Group Decision \& Negotiation, 16(6), 485-506. https://doi.org/10.1007/s10726-006-9068-0

Golany, B., \& Kress, M. A. (1993). Multicriteria evaluation of methods for obtaining weights from ratioscale matrices. European Journal of Operational Research, 69(2), 210-220. https://doi.org/10.1016/0377-2217(93)90165-J

Hahn, E. D. (2003). Decision making with uncertain judgments, a stochastic formulation of the analytic hierarchy process. Decision Sciences, 34(3), 443-466. https://doi.org/10.1111/j.1540-5414.2003.02274.x

Hauser, D., \& Tadikamalla, P. (1996). The analytic hierarchy process in an uncertain environment, a simulation approach. European Journal of Operational Research, 91(1), 27-37. https://doi.org/10.1016/0377-2217(95)00002-X

Herrera-Viedma, E., Herrera, F., \& Chiclana, F. (2002). A consensus model for multiperson decision making with different preference structures. IEEE Transactions on Systems Man \& Cybernetics Part A Systems \& Humans, 32(3), 394-402. https://doi.org/10.1109/TSMCA.2002.802821

Honert, R. C. V. D. (1998). Stochastic group preference modelling in the multiplicative AHP, a model of group consensus. European Journal of Operational Research, 110(1), 99-111. https://doi.org/10.1016/S0377-2217(97)00243-9

Hughes, W. R. (2009). A statistical framework for strategic decision making with AHP, probability assessment and Bayesian revision. Omega, 37(2), 463-470. https://doi.org/10.1016/j.omega.2007.07.002

Jalao, E. R., Wu, T., \& Dan, S. (2014). A stochastic AHP decision making methodology for imprecise preferences. Information Sciences, 270, 192-203. https://doi.org/10.1016/j.ins.2014.02.077

Jin, F., Ni, Z., Chen, H., \& Li, Y. (2016). Approaches to group decision making with intuitionistic fuzzy preference relations based on multiplicative consistency. Knowledge-Based Systems, 97, 48-59. https://doi.org/10.1016/j.knosys.2016.01.017

Jin, F., Ni, Z., Pei, L., et al. (2019). A decision support model for group decision making with intuitionistic fuzzy linguistic preferences relations. Neural Computing and Applications, 31, 1103-1024. https://doi.org/10.1007/s00521-017-3071-z

Jong, P. D. (1984). A statistical approach to Saaty's scaling method for priorities. Journal of Mathematical Psychology, 28(4), 467-478. https://doi.org/10.1016/0022-2496(84)90013-0

Kou, G., Lu, Y., Peng, Y., \& Shi, Y. (2012). Evaluation of classification algorithms using MCDM and rank correlation. International Journal of Information Technology \& Decision Making, 11(1), 197-225. https://doi.org/10.1142/S0219622012500095

Kou, G., Peng, Y., \& Wang, G. (2014). Evaluation of clustering algorithms for financial risk analysis using MCDM methods. Information Sciences, 275(11), 1-12. https://doi.org/10.1016/j.ins.2014.02.137

Kou, G., Ergu, D., Chen, Y., \& Lin, C. (2016). Pairwise comparison matrix in multiple criteria decision making. Technological and Economic Development of Economy, 22(5), 738-765. https://doi.org/10.3846/20294913.2016.1210694

Kou, G., Yang, P., Peng, Y., Xiao, F., Chen, Y., \& Alsaadi, F. E. (2019). Evaluation of feature selection methods for text classification with small datasets using multiple criteria decision-making methods. Applied Soft Computing Journal. https://doi.org/10.1016/j.asoc.2019.105836 
Li, Y., Zhang, H., \& Dong, Y. (2017). The interactive consensus reaching process with the minimum and uncertain cost in group decision making. Applied Soft Computing, 60, 202-212. https://doi.org/10.1016/j.asoc.2017.06.056

Li, G., Kou, G., \& Peng, Y. (2018). A group decision making model for integrating heterogeneous information. IEEE Transactions on Systems, Man, and Cybernetics, Systems, 48(6), 982-992. https://doi.org/10.1109/TSMC.2016.2627050

Lin, C., Kou, G., \& Ergu, D. (2013). An improved statistical approach for consistency test in AHP. Annals of Operations Research, 211(1), 289-299. https://doi.org/10.1007/s10479-013-1413-5

Lin, C., \& Kou, G. (2015). Bayesian revision of the individual pair-wise comparison matrices under consensus in AHP-GDM. Applied Soft Computing, 35(C), 802-811. https://doi.org/10.1016/j.asoc.2015.02.041

Lipovetsky, S., \& Tishler, A. (1999) Interval estimation of priorities in the AHP. European Journal of Operational Research, 114(1), 153-164. https://doi.org/10.1016/S0377-2217(98)00012-5

Liu, J., Song, J., Xu, Q., Tao, Z., \& Chen, H. (2019). Group decision making based on DEA crossefficiency with intuitionistic fuzzy preference relations. Fuzzy Optimization and Decision Making, 18(3), 345-370. https://doi.org/10.1007/s10700-018-9297-0

Moreno-Jiménez, J. M. (2011). An AHP/ANP multicriteria methodology to estimate the value and transfers fees of professional football players. In Proceedings ISAHP. Sorrento, Italia.

Press, S. J. (1989). Bayesian statist, principle, models and applications. John Wiley \& Sons.

Ramanathan, R., \& Ganesh, L. S. (1994). Group preference aggregation methods employed in AHP, An evaluation and an intrinsic process for deriving members' weightages. European Journal of Operational Research, 79(2), 249-265. https://doi.org/10.1016/0377-2217(94)90356-5

Rosenbloom, E. S. (1996). A probabilistic interpretation of the final rankings in AHP. European Journal of Operational Research, 96(2), 371-378. https://doi.org/10.1016/S0377-2217(96)00049-5

Saaty, T. L. (1977). A scaling method for priorities in hierarchical structures. Journal of Mathematical Psychology, 15(3), 234-281. https://doi.org/10.1016/0022-2496(77)90033-5

Saaty, T. L. (1980). The analytic hierarchy process. McGraw-Hill. https://doi.org/10.21236/ADA214804

Schotten, P. C., \& Morais, D. C. (2019). A group decision model for credit granting in the financial market. Financial Innovation, 5, 6. https://doi.org/10.1186/s40854-019-0126-4

Srdjevic, B., \& Srdjevic, Z. (2013). Synthesis of individual best local priority vectors in AHP-group decision making. Applied Soft Computing Journal, 13(4), 2045-2056.

https://doi.org/10.1016/j.asoc.2012.11.010

Vargas, L. G. (1982). Reciprocal matrices with random coefficients. Mathematical Modelling, 3(1), 6981. https://doi.org/10.1016/0270-0255(82)90013-6

Wu, W., \& Kou, G. (2016). A group consensus model for evaluating real estate nvestment alternatives. Financial Innovation, 2, 8. https://doi.org/10.1186/s40854-016-0027-8

$\mathrm{Wu}, \mathrm{Z}$., \& Xu, J. (2012). A consensus and consistency based decision support model for group decision making with multiplicative preference relations. Decision Support Systems, 52(3), 757-767. https://doi.org/10.1016/j.dss.2011.11.022

Wu, P., Zhou, L., Chen, H., \& Tao, Z. (2019). Additive consistency of hesitant fuzzy linguistic preference relation with a new expansion principle for hesitant fuzzy linguistic term sets. IEEE Transactions on Fuzzy Systems, 27(4), 716-730. https://doi.org/10.1109/TFUZZ.2018.2868492

Xu, Z., \& Wei, C. (1999). A consistency improving method in the analytic hierarchy process. European Journal of Operational Research, 116(2), 443-449. https://doi.org/10.1016/S0377-2217(98)00109-X

Zhang, H., Kou, G., \& Peng, Y. (2019). Soft consensus cost models for group decision making and economic interpretations. European Journal of Operational Research, 277(3), 964-980.

https://doi.org/10.1016/j.ejor.2019.03.009 